\title{
Neonatal sepsis: within and beyond China
}

\author{
Ying Dong', Romain Basmaci, ${ }^{2,3}$, Luigi Titomanlio ${ }^{4}$, Bo Sun ${ }^{5}$, Jean-Christophe Mercier ${ }^{6}$ \\ ${ }^{1}$ Department of Neonatology, Children's Hospital of Fudan University, Shanghai 201102, China; \\ ${ }^{2}$ Université de Paris, IAME, INSERM, 75018 Paris, France; \\ ${ }^{3}$ Service de Pédiatrie-Urgences, AP-HP, Hôpital Louis-Mourier, 92700 Colombes, France; \\ ${ }^{4}$ Pediatric Emergency Department, Robert Debre University Hospital, 75019 Paris, France; \\ ${ }^{5}$ Departments of Pediatrics and Neonatology, Children's Hospital of Fudan University, Shanghai 201102, China; \\ ${ }^{6}$ Medical University of Paris, 75018 Paris, France.
}

\begin{abstract}
Sepsis remains a significant cause of neonatal morbidity and mortality in China. A better understanding of neonatal sepsis in China as compared with other industrialized and non-industrialized countries may help optimize neonatal health care both regionally and globally. Literature cited in this review was retrieved from PubMed using the keywords "neonatal sepsis," "early-onset (EOS)" and "late-onset (LOS)" in English, with the focus set on population-based studies. This review provides an updated summary regarding the epidemiology, pathogen profile, infectious work-up, and empirical treatment of neonatal sepsis within and beyond China. The incidence of neonatal EOS and the proportion of Group B Streptococcus (GBS) within pathogens causing EOS in China seem to differ from those in developed countries, possibly due to different population characteristics and intrapartum/postnatal health care strategies. Whether to adopt GBS screening and intrapartum antibiotic prophylaxis in China remains highly debatable. The pathogen profile of LOS in China was shown to be similar to other countries. However, viruses as potential pathogens of neonatal LOS have been underappreciated. Growing antimicrobial resistance in China reflects limitations in adapting antibiotic regimen to local microbial profile and timely cessation of treatment in non-proven bacterial infections. This review stresses that the local epidemiology of neonatal sepsis should be closely monitored in each institution. A prompt and adequate infectious work-up is critically important in diagnosing neonatal sepsis. Adequate and appropriate antibiotic strategies must be overemphasized to prevent the emergence of multi-resistant bacteria in China.
\end{abstract}

Keywords: Antibiotic resistance; Blood culture; Early-onset sepsis; Late-onset sepsis; Neonatal sepsis; Nosocomial neonatal sepsis

\section{Introduction}

Neonatal sepsis is a cause of significant morbidity and mortality. Based on population-level studies during the last two decades, the global estimate of the incidence of neonatal sepsis was 2202 (95\% confidence interval [CI] 1099-4360) per 100,000 live births (LBs), with mortality between $11 \%$ and $19 \% .^{[1,2]}$ In China, birth populationbased surveys from one region that have approximated national average levels estimated the incidence of neonatal sepsis to be 25.6 per 1000 LBs. $^{[3]}$ Between 1996 and 2015, the cause-specific mortality of neonatal sepsis in China decreased from 0.4 to 0.1 per 1000 LBs, which was significantly lower than the global estimate of 2.8 per 1000 LBs in $2015 .{ }^{[4]}$ Notably, great inequity exists in mortality rate of neonatal sepsis across regions in China. ${ }^{[4]}$

\begin{tabular}{|l|l|}
\hline \multicolumn{2}{|c|}{ Access this article online } \\
\hline \multirow{3}{*}{ Quick Response Code: } & $\begin{array}{l}\text { Website: } \\
\text { www.cmj.org }\end{array}$ \\
\cline { 2 - 2 } & $\begin{array}{l}\text { DOI: } \\
10.1097 / C M 9.0000000000000935\end{array}$ \\
\hline
\end{tabular}

Clinical signs of neonatal sepsis range from sub-clinical infection to severe manifestations of focal or systemic disease. ${ }^{[5]}$ The pathogens responsible for sepsis might be acquired through in utero infection, ${ }^{[6]}$ maternal microbiota during delivery, or postnatal hospital or community environment. ${ }^{[7]}$ The timing of the exposure, inoculum size, immune status of the infant, and virulence of the causative micro-organism may greatly influence the clinical manifestations of neonatal sepsis. Based on different definitions across regions, early-onset sepsis (EOS) occurs within the first 3 to 6 days of life, whereas late-onset sepsis (LOS) occurs after 4 to 7 days within the first 1 to 3 months of life. ${ }^{[5]}$ Apart from the onset of time, there are marked differences in terms of pathogen profile and antimicrobial susceptibility among EOS, community-acquired LOS, and hospital-acquired LOS. ${ }^{[7,8]}$ In light of the above, great challenges exist to manage and reduce neonatal sepsis.

Correspondence to: Prof. Jean-Christophe Mercier, Medical University of Paris, 16 rue Henri Huchard, 75018 Paris, France

E-Mail: jean-christophe.mercier@sfr.fr

Copyright $\odot 2020$ The Chinese Medical Association, produced by Wolters Kluwer, Inc. under the CC-BY-NC-ND license. This is an open access article distributed under the terms of the Creative Commons Attribution-Non Commercial-No Derivatives License 4.0 (CCBY-NC-ND), where it is permissible to download and share the work provided it is properly cited. The work cannot be changed in any way or used commercially without permission from the journal.

Chinese Medical Journal 2020; Vol(No)

Received: 04-02-2020 Edited by: Li-Min Chen and Peng Lyu 
China is one of the most populous countries in the world with some regions closely approaching industrialized countries in terms of socioeconomic development and health care, while some relatively lagging behind. The second-child policy since 2015 may further complicate the clinical picture of neonatal sepsis. Therefore, this review will provide an updated summary regarding important aspects of neonatal sepsis, such as epidemiology, pathogen profile, infectious work-up, and empirical treatment, both within and beyond China, in the hope of optimizing neonatal health care both regionally and globally.

\section{Early-Onset Neonatal Sepsis}

\section{Incidences and pathogen profiles}

\section{Industrialized countries}

In developed countries like USA, although the overall incidence of EOS has remained relatively stable at around 0.8 cases per 1000 LBs over the last two decades, ${ }^{[9]}$ there have been marked changes in the pathogen-specific incidence of
EOS. Group B Streptococcus (GBS) and Escherichia coli are predominant pathogens of neonatal EOS, accounting for $36 \%$ and $25 \%$ of EOS cases identified in four US States from 2005 to $2014 .^{[9]}$ Particularly, in the National Institute of Child Health and Human Development birth cohort of very low birth weight (VLBW) infants, there was a marked reduction in EOS caused by GBS (from 5.9 to 2.08 per 1000 LBs, $P<0.001$ ), but an increase in E. coli sepsis (from 3.2 to 5.09 per 1000 LBs, $P=0.004$ ) between $1991-1993$ and 2006-2009. ${ }^{[10,11]}$ In contrast, the incidence of GBS EOS plateaued or even slightly increased in some other developed countries [Table 1]. ${ }^{[12,13]}$ It has been speculated that different population structure, emergence of new GBS clones, increased recognition of EOS symptoms, and modified criteria for diagnosing neonatal sepsis might have contributed to higher incidence of GBS EOS over time in some regions. ${ }^{[13]}$

\section{Non-industrialized countries}

In contrast, the incidence of neonatal GBS EOS is less clear in developing countries, mainly due to limitations in

\begin{tabular}{|c|c|c|c|c|c|c|}
\hline Network & Birth year & $\begin{array}{l}\text { Population } \\
\text { of cohort }\end{array}$ & $\begin{array}{l}\text { No. of } \\
\text { neonates }\end{array}$ & $\begin{array}{l}\text { Onset of } \\
\text { EOS (days) }\end{array}$ & $\begin{array}{l}\text { Incidence of EOS } \\
\text { (per } 1000 \text { LBs) }\end{array}$ & $\begin{array}{l}\text { Case fatality } \\
n / N, \%\end{array}$ \\
\hline \multicolumn{7}{|l|}{ USA } \\
\hline \multirow[t]{2}{*}{$\mathrm{NICHD}^{[10]}$} & 1991-1993 & VLBW & 7606 & $\leq 3$ & $\begin{array}{l}\text { All pathogens: } 19.3 \\
\text { GBS: } 5.9 \\
\text { E. coli: } 3.2\end{array}$ & NA \\
\hline & $1998-2000$ & VLBW & 5447 & $\leq 3$ & $\begin{array}{l}\text { All pathogens: } 15.4 \\
\text { GBS: } 1.7 \\
\text { E. coli: } 6.8\end{array}$ & $31 / 84,37 \%$ \\
\hline \multirow[t]{2}{*}{$\mathrm{NICHD}^{[11]}$} & 2006-2009 & All LBs & 396,586 & $\leq 3$ & $\begin{array}{l}\text { All pathogens: } 0.98 \\
\text { GBS: } 0.41 \\
\text { E. coli: } 0.28\end{array}$ & $\begin{array}{c}61 / 389,16 \% \\
15 / 160,9 \% \\
35 / 107,33 \%\end{array}$ \\
\hline & & VLBW & 12,956 & $\leq 3$ & $\begin{array}{l}\text { All pathogens: } 10.96 \\
\text { GBS: } 2.08 \\
\text { E. coli: } 5.09\end{array}$ & NA \\
\hline \multicolumn{7}{|l|}{ UK } \\
\hline CoSurv $^{[12]}$ & 2000-2001 & All LBs & 794,037 & $\leq 6$ & GBS: 0.48 & $38 / 377,10.6 \%$ \\
\hline NeonIN $^{[13]}$ & 2006-2008 & All LBs & 130,763 & $\leq 2$ & $\begin{array}{l}\text { All pathogens: } 0.9 \\
\text { GBS: } 0.5 \\
\text { E. coli: } 0.2\end{array}$ & NA \\
\hline $\mathrm{BPSU}^{[20]}$ & 2014-2015 & $\begin{array}{l}\text { All LBs } \\
\text { VLBWs }\end{array}$ & $\begin{array}{l}914,132 \\
7569\end{array}$ & $\begin{array}{l}\leq 6 \\
\leq 6\end{array}$ & $\begin{array}{l}\text { GBS: } 0.57 \\
\text { GBS: } 2.24\end{array}$ & $27 / 517,5.2 \%$ \\
\hline \multicolumn{7}{|l|}{ The Netherlands } \\
\hline AMC-RVIM $^{[19]}$ & $\begin{array}{l}1987-1999 \\
2000-2011\end{array}$ & $\begin{array}{l}\text { All LBs } \\
\text { All LBs }\end{array}$ & $\begin{array}{l}\text { NA } \\
\text { NA }\end{array}$ & $\begin{array}{l}<7 \\
<7\end{array}$ & $\begin{array}{l}\text { GBS: } 0.11 \\
\text { GBS: } 0.19\end{array}$ & NA \\
\hline \multicolumn{7}{|l|}{ Asia } \\
\hline $\begin{array}{l}\text { Five NICUs }{ }^{[15]} \\
\text { in China, Kuwait, } \\
\text { Malaysia, Thailand }\end{array}$ & 2005 & All LBs & 35,294 & $\leq 2$ & $\begin{array}{l}\text { All pathogens: } 0.72 \\
\text { GBS: } 0.51 \\
\text { GNB: } 0.15\end{array}$ & $\begin{array}{c}6 / 47,12.8 \% \\
4 / 18,22 \% \\
2 / 17,12.5 \%\end{array}$ \\
\hline $\begin{array}{l}\text { Three NICUs }{ }^{[16]} \\
\text { in China, Malaysia, } \\
\text { Thailand }\end{array}$ & 2006-2009 & All LBs & 76,141 & $<3$ & $\begin{array}{l}\text { All pathogens: } 0.62 \\
\text { GBS } 0.24 \\
\text { GNB: } 0.11\end{array}$ & $13 / 181,7.2 \%$ \\
\hline China $^{[17]}$ & $2015-2018$ & All LBs $<34$ weeks & 19,084 & $<3$ & All pathogens: 9.7 & $42 / 186,22.6 \%$ \\
\hline
\end{tabular}

EOS: Early-onset sepsis; LBs: Live births; NICHD: National Institute of Child Health and Human Development; BPSU: British Paediatric Surveillance Unit; AMC-RVIM: Netherlands Reference Laboratory for Bacterial Meningitis of the Amsterdam Medical Center and the National Institute of Public Health and the Environment; NICU: Neonatal intensive care unit; VLBW: Very low birth weight; NA: Not available; GBS: Group B Streptococcus; GNB: Gram-negative bacilli. 
detection methodology as well as difficulties in defining population denominator. ${ }^{[14]}$ Although not based on nationwide surveillance system, two consecutive prospective multi-center studies in Asia have shed some light on the trend of neonatal EOS in this region, showing a steady decline in overall as well as pathogen-specific incidence of EOS from 2005 to 2009 [Table 1]. ${ }^{[15,16]}$ Meanwhile, the overall case fatality of EOS decreased by nearly $40 \%$ [Table 1]. ${ }^{[15,16]}$ Moreover, EOS in developing countries may have different pathogen profiles. Based on a recent multicenter study including preterm infants $<34$ weeks' gestation admitted to 25 tertiary neonatal units in China (2015-2018), the incidence of EOS was 11.7 cases per 1000 admissions $(321 / 27,532)$ or 9.7 cases per 1000 LBs if only inborn infants in 18 perinatal centers were considered $(186 / 19,084) .{ }^{[17]}$ The leading pathogen was Gram-negative bacteria (GNB) like E. coli $(20.3 \%)$, followed by coagulase-negative staphylococci (CoNS) $(16.5 \%)$, whereas EOS caused by GBS was relatively rare $(2.5 \%))^{[17]}$ The case fatality rate of EOS in China was $19 \%(61 / 321) .{ }^{[17]}$

\section{Intrapartum antibiotic prophylaxis (IAP) for EOS}

\section{The US}

As the primary risk factor for neonatal GBS EOS is maternal colonization of the genitourinary and gastrointestinal tracts, the American College of Obstetricians and Gynecologists (ACOG) recommends universal maternal screening by vaginal-rectal culture between 36 and 38 weeks of gestation to effectively prevent GBS EOS [Supplementary Figure 1A-1C, http://links.lww.com/ CM9/A244, http://links.lww.com/CM9/A245, http://links. lww.com/CM9/A246]. ${ }^{[18]}$ Approximately 50\% of women who are colonized with GBS will transmit the bacteria to their newborns. ${ }^{[18]}$ Vertical transmission usually occurs during labor or after preterm premature rupture of membranes. ${ }^{[6]}$ In the absence of IAP, $1 \%$ to $2 \%$ of these newborns will develop GBS EOS. ${ }^{[18]}$ All women whose vaginal-rectal cultures are positive for GBS should receive appropriate IAP, mostly penicillin or amoxicillin, unless a pre-labor caesarian section is performed in the setting of intact membranes. ${ }^{[18]}$ Although a shorter duration of recommended intrapartum antibiotics less than $4 \mathrm{~h}$ may not be as effective as that of more than $4 \mathrm{~h}, 2 \mathrm{~h}$ of antibiotic exposure has been shown to reduce GBS vaginal colony counts and decrease the frequency of a clinical neonatal sepsis diagnosis. Obstetrical interventions, whenever necessary, should not be delayed in order to provide the 4-h antibiotic administration before birth. ${ }^{[18]}$

\section{Europe}

In contrast to universal maternal screening, risk-based stratification has been adopted in other industrialized countries. $^{[12,13,19]}$ Based on a prospective national surveillance of invasive GBS in infants younger than 90 days from 2014 to 2015 in the UK and Ireland, the incidence of all GBS infection was 0.94 (95\% CI 0.88-1.00) per $1000 \mathrm{LBs}$, with GBS EOS being 0.57 (95\% CI 0.52-0.62) per 1000 LBs. ${ }^{[20]}$ The case fatality rate of GBS EOS was $5.2 \%$, lower than that in the US [Table 1]. ${ }^{[10,11,20]}$ Notably, both the incidence and case fatality rate were about five-fold higher in VLBW infants than in those with a BW $>1500 \mathrm{~g}$. In the Netherlands, despite IAP guidelines to prevent GBS EOS on the basis of culture-based screening at 35 to 37 week's gestation, the incidence of GBS EOS increased slightly over the last two decades, demonstrating a similar secular trend as in the UK [Table 1]. ${ }^{[19]}$ In the UK, five serotypes (Ia, Ib, II, III, V) accounted for $377(94 \%)$ of all isolates GBS strains, with the predominant serotypes being III $(60 \%)$ and Ia $(17 \%) .{ }^{[20]} \mathrm{A}$ particular concern is the large number of isolates identified as sequence type (ST)17, a clone associated with a high risk of invasive neonatal sepsis and meningitis. ${ }^{[21]}$ Thus, much hope lies on a vaccine against GBS which is still under development. ${ }^{[22]}$

\section{China}

Currently, no standard guidelines exist for maternal GBS screening and neonatal GBS disease prevention in China. While some hospitals perform IAP following a risk-based strategy, others apply universal screening recommended by ACOG. A recent systematic review of published data from Chinese literature revealed that the maternal GBS colonization rate in the mainland of China may range from $5.7 \%$ to $14.5 \%$ among institutions. ${ }^{[23]}$ Based on so far the largest population-based surveillance study for GBS disease burden from 18 urban tertiary hospitals across 16 Chinese provinces (2015-2017), the overall incidence of invasive GBS disease in infants $\leq 3$ months of life was estimated to be 0.31 (95\% CI $0.27-0.36$ ) cases per 1000 LBs, ranging from 0 to 76 cases per 1000 LBs across participating hospitals. ${ }^{[24]}$ The incidence of early- and lateonset GBS disease was 0.18 (95\% CI 0.15-0.22) and 0.13 $(95 \% 0.11-0.16)$ per $1000 \mathrm{LBs}$, respectively. ${ }^{[24]}$ The majority $(76.6 \%)$ of invasive GBS disease occurred in term infants, and only $13.2 \%$ of GBS-case mothers received GBS screening during pregnancy. ${ }^{[2]}$ Similar to the UK, five serotypes (Ia, Ib, II, III, and V) accounted for the majority of GBS invasive cases in the mainland of China, and isolated GBS strains were most commonly III serotype and ST 17. ${ }^{[23,24]}$ Due to population characteristics and sociocultural background, the actual rate of maternal GBS colonization and neonatal GBS diseases in China may differ greatly from those reported in industrialized countries, and are probably much lower based on current knowledge. Unresolved issues remain as to whether GBS screening and prevention protocols should be incorporated in China, and if so, what kind of strategies. As such, immunizing pregnant women against GBS, despite being an emerging approach to protect neonates from GBS disease in some countries, could not yet be introduced in China.

So far, chorioamnionitis as a significant risk factor of neonatal EOS has not been fully appreciated in China. It has been suggested that pathological and microbiological examination of the placenta should be routinely performed, especially in preterm deliveries, in order to better assess EOS and combined perinatal co-morbidities. ${ }^{[25]}$ Notably, the predominance of nosocomial and opportunistic pathogens (eg, GNB and CoNS) among neonatal EOS cases in China raised the concern of possible unhygienic practices or inappropriate perinatal exposure to antibiotics favoring intestinal translocation of GNB..$^{[17]}$ 
Late-Onset Neonatal Sepsis

\section{Maternal post-partum transmission of GBS is underestimated}

LOS still accounts for about one-third of neonatal GBS sepsis, and the case fatality rate of GBS LOS was higher than that of GBS EOS $\left(7.7 \%\right.$ vs. 5.2\%). ${ }^{[20]}$ Mother-toinfant transmission may constitute an important source of GBS LOS. A longitudinal study was carried out in 160 mother-baby pairs from Italy to assess postnatal colonization with GBS and the impact of IAP. ${ }^{[26]}$ Specimens from the rectum, vagina, and milk of mothers were collected from the time of delivery to 8 weeks post-partum. Women were grouped into culture-positive carriers $(n=83)$, culture-negative carriers $(n=26)$, and non-carriers $(n=51)$ at discharge from hospital. A total of $35(22 \%)$ neonates were colonized by GBS from at least one body site, and the majority of them (30/35) were born to culturepositive carriers. Infants of culture-positive carriers exposed to IAP were less likely to be colonized $(15 / 57$ vs. $15 / 26, P=0.01)$, or heavily colonized $(7 / 57$ vs. $1 / 26$, $P=0.04)$. However, neonates exposed to IAP and discharged GBS-free from hospital often became subsequently colonized $(12 / 57 v s .1 / 26, P=0.09)$, and six out of 83 culture-positive carrier mothers showed positive milk cultures with heavy colonization of GBS in their babies. Molecular typing analysis confirmed identical GBS strains in all mother-baby pairs. These data call the attention of physicians to maternal transmission after delivery as an underestimated source of neonatal LOS.

\section{GNB are associated with severe neonatal LOS}

Despite being less common than Gram-positive bacteria to cause neonatal LOS, GNB are associated with more severe clinical manifestations such as meningitis, and have a higher mortality, especially in VLBW infants. ${ }^{[27]} E$. coli is the most common cause of bacterial meningitis in preterm infants and the second most common after GBS in term neonates in the UK. ${ }^{[28]}$ In France, the average number of LBs each year was around 800,000 between 2001 and 2013 , of whom $6.6 \%$ were born preterm. ${ }^{[29]}$ In 2001 , the Pediatric Infectious Group of the French Pediatric Society (GPIP/ACTIV) established an active bacterial pediatric meningitis surveillance network including 233 pediatric wards and 168 microbiology laboratories. From 2001 to 2013, 325 infants were prospectively diagnosed with E. coli meningitis, which was seven-fold more frequent in preterm than in term infants. ${ }^{[30]}$ The median age at diagnosis was 14 days, with two peaks of infection onset at 0 to 3 days of age (EOS in mostly preterm neonates), and 11 to 15 days of age (LOS in mostly term infants). Severe clinical manifestation was reported in $51.9 \%$ of patients, and $9.2 \%$ died. Death was associated with very preterm birth (odds ratio [OR]: 7.3, 95\% CI 2.7-20.9; $P<0.001$ ), cerebrospinal fluid (CSF) to blood glucose ratio $<0.1$ (OR: $15.3,95 \%$ CI $1.8-128.3 ; P=0.012)$, uncommon strains like O7 serogroup $(P=0.034)$, and PapGII adhesin (OR: $2.3,95 \%$ CI $1.2-4.5 ; P=0.015)$. Translocation of GNB into the systemic circulation via an interrupted gastrointestinal barrier has been speculated to be a key mechanism of GNB LOS. ${ }^{[27,31]}$

\section{Pathogen profiles of community- and hospital-acquired neonatal LOS}

An emerging body of evidence has demonstrated completely different microbiological findings between various types of sepsis. This is of critical importance to guide empirical antibiotic therapy strategy, which should not only be adapted to the timing (early vs. late), but also to circumstances (hospital- $v$ s. community-acquired).

\section{Industrialized countries}

To assess the epidemiology and types of neonatal sepsis, all newborn infants with blood culture-proven sepsis admitted to neonatal intensive care units (NICUs) in Switzerland between 2011 and 2015 were included. ${ }^{[7]}$ Infants with LOS were classified as community- or hospital-acquired LOS if onset of infection was $\leq 48$ or $>48 \mathrm{~h}$ following admission. In 429 infants there were 444 episodes of blood culture-proven sepsis, with $20 \%, 62 \%$, and $18 \%$ being EOS, hospital-acquired LOS, and community-acquired LOS, respectively. Correspondingly, the estimated incidence was $0.28,0.86$, and 0.28 per $1000 \mathrm{LBs}$, and case fatality $18 \%, 12 \%$, and $0 \%$, respectively. Major pathogens were GBS, other Gram-positive bacteria, and E. coli for EOS; GBS and E. coli for community-acquired LOS. In contrast, CoNS, Staphylococcus aureus, and other GNB were mostly isolated in hospital-acquired LOS [Supplementary Figure 2A, http://links.lww.com/CM9/A247 and 2B, http://links.lww.com/CM9/A248]. ${ }^{[7]}$

\section{Non-industrialized countries}

The burden of neonatal infections in developing countries is highly variable, maybe because of the lack of vital registries and surveillance systems. ${ }^{[32]}$ Information about community-acquired bacteremia in South Asia and Southeast Asia was approached through a review of 17 eligible studies enrolling 40,644 patients. ${ }^{[33]}$ Pathogenic organisms were isolated in $1722(7 \%)$ of 26,258 children. Salmonella enterica serotype Typhi was the most common bacterial pathogen. Other commonly isolated organisms in children were Streptococcus pneumoniae and Haemophilus influen$z a e$, probably reflecting the lack of large-sale vaccination. Severe bacterial infections are a leading cause of death among neonates in low-income countries with poor hygiene and frequent exposure to antibiotics without documentation of bacterial infection, resulting in the emergence and spread of multi-resistant bacteria. ${ }^{[34]}$ With advancing pediatric healthcare, the use of central venous catheters (CVC) has become a fundamental part of neonatal and pediatric intensive care. ${ }^{[35]}$ Maximal sterile barrier precautions have been shown to independently contribute to decreased CVC-associated bloodstream infection in VLBW infants. ${ }^{[36]}$ Currently, there is a lack of population-based data on the pathogen profile of neonatal LOS in China. Gram-positive bacteria, mainly CoNS and S. aureus, were indicated as being responsible for the majority of neonatal LOS, while E. coli and Klebsiella spp. may account for most GNB LOS. ${ }^{[16,37-41]}$. Most hospital-acquired LOS occurred in very preterm infants who were very likely to receive some kind of ventilatory support and parenteral nutrition through a CVC. ${ }^{[42]}$ 


\section{Neonatal Viral Sepsis}

\section{The incidence of overall viral sepsis}

Viruses are common but largely underappreciated pathogens of neonatal sepsis. In a population-based pregnancy surveillance at five sites in Bangladesh, India, and Pakistan from 2011 to 2014, babies with illnesses meeting the World Health Organization definition of possible serious bacterial infections (pSBI) were referred to study physicians for culture and molecular assays of blood and respiratory samples. ${ }^{[8]}$ Among 63,114 babies, 6022 pSBI episodes were identified (95.4 per $1000 \mathrm{LBs}$ ), with causes specified in $28 \%$ of episodes $(16 \%$ bacterial and $12 \%$ viral). The mean incidence of bacterial and viral infections was 13.2 (95\% credible interval $11.2-15.6)$ and 10.1 (95\% credible interval 9.4-11.6) per 1000 LBs, respectively. The leading viral pathogen was respiratory syncytial virus (5.4 per $1000 \mathrm{LBs}$ ). This study was among the first to provide valuable population-based data on neonatal viral sepsis with universal detection of pathogen species. So far, species-specific data on neonatal viral sepsis are limited.

\section{Herpes simplex virus (HSV)}

HSV may cause potentially devastating infection in neonates. However, large-scale assessment of its frequency in potentially infected infants has not been performed, apart from one retrospective cross-sectional study in 23 North American pediatric emergency departments enrolling infants $\leq 60$ days old with CSF samples for HSV polymerase chain reaction (PCR) or culture. ${ }^{43]}$ Of 26,533 eligible encounters, 112 infants had HSV identified $(0.4 \%)$, corresponding to $1.2 \%$ of all infants tested for HSV. Among them, $90(80.4 \%)$ occurred in weeks 1 to 4 , with the median age of HSV-infected infants being 14 days (interquartile range 9-24 days). Notably, 68 of 112 testpositive infants had central nervous system (CNS) or disseminated HSV disease. The proportion of infants subjected to an HSV test $(35 \%$, range $14 \%-72 \%)$ and to whom acyclovir was administered $(23 \%$, range $4 \%-53 \%)$ varied widely across centers. Thus, both pediatric emergency physicians and neonatologists should keep in mind this rare but deadly cause of neonatal sepsis, which requires urgent acyclovir administration. A careful review of the maternal history and close communication with obstetricians are critical for a timely diagnosis and treatment of neonatal HSV disease.

\section{Enteroviruses}

Enteroviruses have been increasingly recognized to be causes of meningitis, sepsis-like disease, and fever without source in neonates and older children. A prospective multicenter study performed at 35 French pediatric and emergency departments has shown that positive blood PCR results for enterovirus was common. ${ }^{[4]}$ Between 2015 and 2016, a total of 71 newborns were subjected to enterovirus testing, the detection of enterovirus was more frequent in blood than in CSF (70/71 vs. 62/71, $P=0.011)$. As such, PCR for enterovirus should be part of the sepsis workup in neonatal sepsis, and empiric antibiotic therapy should be promptly discontinued in confirmed cases of viral infection. So far, there is a lack of population-based data on neonatal infection due to enterovirus in China. In a hospital-based prospective study in a level-3 NICU in East China, enterovirus infection among febrile neonates with an admission temperature $>38^{\circ} \mathrm{C}$ was diagnosed by PCR testing of stool and/or CSF samples. ${ }^{[45]}$ One-hundred thirty one $(39.2 \%)$ of 334 febrile neonates had PCRconfirmed enterovirus infection, with PCR results being positive in $130(99.2 \%)$ of stool and in $58(44.3 \%)$ of CSF samples, respectively. Among 131 infected neonates, mostly term infants in their 2 to 3 postnatal weeks, 69 $(52.7 \%)$ had diarrhoea, $48(36.6 \%)$ respiratory symptoms, $22(16.8 \%)$ poor feeding, $34(26.0 \%)$ rash, and 18 $(13.7 \%)$ lower platelet counts $<150 \times 10^{9} / \mathrm{L}$. ${ }^{[4]}$ These data indicate that enterovirus infection may be common in febrile neonates and stool samples should be included in diagnostic work-up. Although all infected patients received supportive treatment with none developing fulminant disease course, the long-term outcome of neonates infected with enterovirus may be worrying. Another case series of 12 Chinese neonates with a GA of 35 to 39 weeks showed that enterovirus can cause severe encephalitis associated with white matter damage in the neonatal period, and the severity of the imaging abnormalities might correlate with later neurodevelopmental outcome. ${ }^{[46]}$

\section{Infectious Work-up of Neonatal Sepsis}

Initial signs and symptoms of neonatal sepsis are often mild and not specific. Infected infants are likely to appear generally ill, without fever or system-related symptoms. However, the disease course may also be fulminant with development of septic shock, respiratory distress, neurological dysfunction, and even death. As such, a prompt and adequate infectious work-up is essential for timely diagnosis of neonatal sepsis and the prevention of adverse outcomes.

\section{Culture-dependent and independent tests}

Sufficient amount $(1-2 \mathrm{~mL})$ of blood should be taken to optimize the yield of blood culture, ${ }^{[47]}$ besides the volume needed for a full blood cell count, venous $\mathrm{pH}$, and lactate, and other parameters to assess the disease status [Table 2]. Urine sample obtained via aseptic bladder catheterization and CSF via lumbar puncture (LP) should be considered in a respiratory- and hemodynamically-stable infant. ${ }^{[4-50]} \mathrm{A}$ positive bacterial culture after 24 to $36 \mathrm{~h}$ confirm the type of bacterial pathogen, and allows antimicrobial susceptibility testing. ${ }^{[42]}$ Biological markers, such as procalcitonin (PCT), C-reactive protein (CRP), white blood cell, and absolute neutrophil count (ANC), are not specific of bacterial infection. However, the Lab-score based on PCT levels $(<0.5, \geq 0.5$, and $\geq 2 \mathrm{ng} / \mathrm{mL})$, CRP levels $(<40,40$ 99 , and $\geq 100 \mathrm{mg} / \mathrm{L}$ ), and urine dipstick (negative or positive) has been shown to be highly predictive of a urinary tract infection (UTI). ${ }^{[51]}$ Nonetheless, UTI should be defined by bacterial counts of uropathogen (mostly E. coli), with the minimum concentration ranging between $10^{5}$ and $10^{6}$ colony-forming units $/ \mathrm{mL} \cdot{ }^{[52]}$ Recently, two prediction rules to identify young febrile infants at risk of SBI in the pediatric emergency department have been validated. The "Step-by-Step" approach developed in 
Table 2: Neonatal sepsis workup.

\begin{tabular}{|c|c|c|c|}
\hline Parameter & Test & $\begin{array}{l}\text { Optimal conditions for specimen } \\
\text { collection }\end{array}$ & Value in diagnosing neonatal sepsis \\
\hline \multicolumn{4}{|l|}{ Infectious markers } \\
\hline Urine & Culture & Bladder catheterization & Gold standard for UTI \\
\hline CSF & Culture & Non-traumatic lumbar puncture & Standard for meningitis \\
\hline Nasopharyngeal & PCR & $\begin{array}{l}\text { Winter epidemics, contact with a } \\
\text { sick case; Nasal aspirates for } \\
\text { RSV, nasal swab for influenza } \\
\text { virus }\end{array}$ & $\begin{array}{l}\text { Discuss plausibility and PCR } \\
\text { positivity: possible respiratory } \\
\text { tract infection }\end{array}$ \\
\hline \multicolumn{4}{|l|}{ Biological markers } \\
\hline pH, ABG, lactate & Blood & Arterial or venous sampling & $\begin{array}{l}\text { Lactate }>2 \mathrm{~mol} / \mathrm{L} \text { (indicate } \\
\text { shock) }\end{array}$ \\
\hline ANC & Blood count & $\begin{array}{l}\text { Take into account the potential } \\
\text { normal range for postnatal age }\end{array}$ & $\begin{array}{l}\text { Neutropenia }<1500 / \mathrm{mm}^{3} \\
\text { (Not specific of bacterial } \\
\text { infection) }\end{array}$ \\
\hline CRP & Blood & $8-24 \mathrm{~h}$ after onset of infection & $>20 \mathrm{mg} / \mathrm{L}$ (not specific) \\
\hline Sepsis scores ${ }^{[53,54]}$ & Multiple test & $24 \mathrm{~h}$ after onset of sepsis & Useful for low-risk SBI \\
\hline
\end{tabular}

CSF: Cerebrospinal fluid; ABG: Arterial blood gases; ANC: Absolute neutrophil count; PCT: Procalcitonin; CRP: C-reactive protein; PCR: Polymerase chain reaction; RSV: Respiratory syncytial virus; UTI: Urinary tract infection; SBI: serious bacterial infection; IF: Immunofluorescence.

Europe assesses abnormal clinical appearance at first, followed by young age $(<3$ weeks), significant leukocyturia and bacteruria confirmed by high-power field microscope, PCT $>0.5 \mathrm{ng} / \mathrm{mL}$, CRP $>20 \mathrm{mg} / \mathrm{L}$, or ANC $>10,000 / \mathrm{mm}^{3}$ to define low-risk and high-risk of SBI. ${ }^{[53]}$ The prediction rule of the PECARN group in USA identifies febrile infants 60 days or younger at low risk of SBI using the urinalysis, ANC, and PCT levels. ${ }^{[54]}$

\section{Particularities of LP}

LP is mandated in young febrile infants if sepsis is highly suspected and the patient's condition allows. ${ }^{[53-55]}$ The previously recommended practice of performing brain imaging before a LP has been shown to significantly delay antibiotic treatment and increase the likelihood of a poor neurologic outcome, both in adults and children with proven bacterial meningitis. ${ }^{[56,57]}$ As a traumatic LP can complicate the interpretation of CSF, it is helpful to evaluate the mean spinal canal depth (MSCD) using either the following rule MSCD $(\mathrm{mm})=0.4 \times$ weight $(\mathrm{kg})+20$ or direct ultrasound imaging. ${ }^{[58]}$ Direct examination of CSF sample under microscope is mandatory to determine the bacterial type and number per high-power field, providing valuable guidance for empirical antibiotic therapy. The presence of Gram-positive cocci in long chains under microscope may suggest GBS meningitis, and Gramnegative bacilli meningitis caused by $E$. coli or even extended-spectrum beta-lactamase (ESBL) Enterobacteriaceae, depending on microbial surveillance results at the local institutions. In a multicenter study in Asia which included 453 documented episodes of neonatal sepsis, the most common pathogens for neonatal meningitis were Klebsiella spp. (27/76), followed by CoNS (11/76) and E. coli (10/76), with GBS identified only in one case. ${ }^{[15]}$
One recent province-level multicenter study in South China including 838 cases of neonatal meningitis from 12 hospitals (2011-2016) showed that the first three causes were GBS (88/249), E. coli (55/249), and CoNS (32/ 249). ${ }^{[59]}$

\section{Empirical Treatment of Neonatal Sepsis}

\section{Timing and regimen of antibiotics}

Empirical antibiotic treatment should be initiated as soon as neonatal sepsis is suspected, in fear of negative outcomes associated with missed septic cases. As streptococci are often sensitive to penicillin/ampicillin and about $50 \%$ of E. coli, noticeably $\mathrm{K} 1$, are resistant to ampicillin/ amoxicillin, most recommendations of treating neonatal EOS are now to combine amoxicillin/ampicillin with gentamicin. ${ }^{[5,60]}$ If culture confirms GBS, amoxicillin/ ampicillin is recommended, and gentamicin should be discontinued after $48 \mathrm{~h}$ to prevent cumulative nephro- and oto-toxicity. ${ }^{[61,62]}$ In case of ampicillin-resistant E. coli infection, a third-generation cephalosporin like cefotaxime should be used (100 mg/kg per day), and at a higher dosage $(200 \mathrm{mg} / \mathrm{kg}$ per day) when meningitis is suspected. In case of hospital-acquired LOS which is often caused by CoNS like Staphylococcus epidermidis, ${ }^{[42]}$ vancomycin by intravenous injection (or continuous infusion through a CVC if it is infected) is recommended at first, ${ }^{[63,64]}$ as many of CoNS are indeed methicillin-resistant. When culture results are positive for GNB, aminoglycoside is preferred given its narrow spectrum and reduced risk of resistance. ${ }^{[5]}$ However, escalation to third-generation cephalosporin and even carbapenem should be considered, depending on local epidemiology, clinical presentation especially with CNS involvement, and whether there is evidence of ESBL Enterobacteriaceae. ${ }^{[5]}$ As community-acquired LOS is 
often related to respiratory viral infections, ${ }^{[65]}$ antibiotic treatment must be rapidly discontinued when viral infections is confirmed by multiplex PCR of nasopharyngeal aspirates.

\section{The duration of antibiotic treatment}

Recently, two statements regarding the management of neonates born at $<35$ and $>35$ weeks' gestation with suspected or proven early-onset bacterial sepsis have been released in the US. ${ }^{[66,67]}$ Suspected EOS should always be confirmed by cultures of blood, urine or CSF, and antibiotic therapy should be discontinued if cultures are sterile. ${ }^{[66,67]}$ This rule also applies to the management of LOS. Furthermore, non-specific biological markers (eg, blood cell count, PCT, CRP) alone do not justify prolonged use of antibiotics. ${ }^{[66,67]} \mathrm{A}$ fruitful dialogue should be maintained between neonatologists and microbiologists to optimize the duration of antibiotic treatment, which relies often upon empirical rules: 7 to 10 days for bacteremia, 14 days for Gram-positive meningitis, and 21 days for Gram-negative meningitis, ${ }^{[3,68]}$ Given the general trend to shorten antibiotic therapy and minimize the selection of multi-resistant bacteria, ${ }^{[69]}$ PCT as a highly sensitive biomarker of sepsis has been investigated to guide the cessation of antibiotic therapy. ${ }^{[70]}$

\section{Overuse and misuse of antibiotics contribute to microbial resistance}

Both the inappropriate overuse of broad-spectrum antibiotics, such as third-generation cephalosporins and carbapenem, and inadequacy of antibiotic stewardship have led to the emergence of multi-resistant bacteria, mostly ESBL Enterobacteriaceae, in neonatal sepsis in China. ${ }^{[71]}$ In a retrospective study reporting the temporal trend of antimicrobial resistance over a period of 25 years in the largest neonatal unit in Southwest China, a dramatic six- and two-fold increase was found in the resistance rate of ceftazidime and imipenem respectively, in Klebsiella spp. isolated from neonates with sepsis. ${ }^{[38]} \mathrm{A}$ recent metaanalysis of Chinese literature (2009-2014) on neonatal sepsis revealed that more than $50 \%$ of E. coli and Klebsiella spp. were resistant to third-generation cephalosporin, and ampicillin resistance of E. coli was almost $80 \%,{ }^{[37]}$ similar to that in the US $(85 \%) \cdot{ }^{[11]}$ Unsurprisingly, the resistance rate of amikacin was relatively low (around 10\%-15\%) in E. coli and Klebsiella spp., ${ }^{[3]}$ probably due to the fact that aminoglycoside is not routinely used to treat neonatal sepsis in China. Carbapenem-resistance was found in $9 \%$ of E. coli and $6 \%$ of Klebsiella spp., respectively. ${ }^{[37]}$ Similar antibiotic susceptibility results of GNB were corroborated by other systematic reviews and web-based surveys. ${ }^{[72,73]}$ As for Gram-positive bacteria, although resistance to glycopeptide including vancomycin and linezolid seem to be rare in China, methicillin resistance was reported for $60 \%$ to $70 \%$ of Staphylococcus spp. ${ }^{[37,38,40]}$

Antimicrobial resistance in developing countries, such as India ${ }^{[74]}$ and Egypt, ${ }^{[75]}$ is alarming. A very recent report from a multinational, multicenter online database showed that third-generation cephalosporin resistance rates among
Gram-negative isolates ranged from $26 \%$ to $84 \%$, and carbapenem resistance rates ranged from $0 \%$ to $81 \%$ in 12 low- and middle-income countries. ${ }^{[73]}$ Glycopeptide resistance rates among Gram-positive bacteria ranged from $0 \%$ to $45 \% .{ }^{[73]}$ Staff to patient ratio and antibiotic availability were considered to be key factors affecting antimicrobial resistance rate in these settings. ${ }^{[73]}$ The rising antibiotic resistance very much complicates both the choice of initial empirical antibiotic treatment and secondary antibiotic strategy, as last-resource antibiotics are not readily accessible in many settings. ${ }^{[76]}$

To minimize the selection of multi-resistant bacteria, there is an urgent need to restrict antibiotic therapy to proven neonatal bacterial infection and shorten antibiotic course. Furthermore, surveillance and assessment of antibiotic consumption has been demonstrated to positively influence antibiotic stewardship strategy and reduce antibiotic use. ${ }^{[77]}$ Screening for GNB on neonatal body sites may have a predictive value in neonatal $\operatorname{LOS},{ }^{[78]}$ and decolonization has been investigated as an approach to prevent sepsis and the spread of multi-resistant GNB. ${ }^{[79]}$ However, the prognostic value of routine screening of neonatal microbial colonization remains controversial, due to a lack of high-quality evidence, especially in VLBW infants. ${ }^{[31,78]}$

\section{Supportive treatment of neonatal sepsis: uncertainties and certainties?}

Neonatal sepsis can progress to septic shock, which may requires volume loading and vasopressors in order to maintain organ function. However, after the publication of the paradoxical results of the fluid expansion as supportive treatment (FEAST) trial comparing repeated boluses of 20 $\mathrm{mL} / \mathrm{kg}$ of either saline or $5 \%$ albumin with no bolus in 3141 African children with severe infection, ${ }^{[80]}$ there is now a trend to restrict unnecessary volume loading in order to stabilize hemodynamics while preventing the occurrence of brain and lung edema, especially in resourcelimited settings. ${ }^{[81]}$

For years, intravenous immunoglobulins (IVIG) have been used in severe neonatal sepsis, because newborns are relatively deficient in endogenous immunoglobulins. However, a large phase III clinical trial of 3493 infants at 113 hospitals comparing two iv infusions of $500 \mathrm{mg}$ $(10 \mathrm{~mL})$ per kg body weight $48 \mathrm{~h}$ apart with placebo failed to demonstrate a significant difference in the incidence of subsequent sepsis episodes and the rates of major or nonmajor disability at 2 years of follow-up. ${ }^{[82]}$ Since the large clinical trial included neonates from both developing and developed countries, the negative results should be interpreted as high-level evidence to abandon IVIG administration among septic neonates in China.

\section{Conclusions}

To sum up, the epidemiology and pathogen profile of neonatal sepsis may differ substantially between countries and regions, and data from elsewhere should always be interpreted with caution before being extrapolated to any local institution in China. The alarmingly high 
antimicrobial resistance rate of pathogens causing neonatal sepsis in China poses a substantial challenge, given its very large annual birth population. ${ }^{[83]}$ Emphasis is laid on continuous monitoring of a priori antibiotic susceptibility of the causative micro-organisms. Notably, viral infection may mimic clinical signs of bacterial sepsis but require antiviral therapy (or no therapy) instead of antibiotics. There is an urgent need for the early diagnosis of neonatal sepsis followed by adequate and appropriate empirical therapy. Equally important is the early cessation of antimicrobial treatment as soon as negative microbial evidence has been yielded, despite the presence of isolated abnormal inflammatory markers. Last but not the least, efficient communication with both obstetricians for reliable maternal history and microbiologists for culture results is strongly recommended, especially in resource-limited settings in China, to optimize the regimen and duration of antibiotic treatment.

\section{Acknowledgements}

The authors would like to warmly thank Dr. Robert RossRussell, Director of Studies in Medicine, Peterhouse, Cambridge, UK, and Chair of the European Board of Pediatrics for his kind editorial assistance. We also thank Wolters Kluwer Health, Inc. and Elsevier for authorizing the citation of Supplementary Figures 1, http://links.lww. com/CM9/A244, http://links.lww.com/CM9/A245, http:// links.lww.com/CM9/A246 and 2, http://links.lww.com/ CM9/A247, http://links.lww.com/CM9/A248 in our manuscript.

\section{Conflicts of interest}

None.

\section{References}

1. Liu L, Oza S, Hogan D, Chu Y, Perin J, Zhu J, et al. Global, regional, and national causes of under-5 mortality in 2000-15: an updated systematic analysis with implications for the sustainable development goals. Lancet 2016;388:3027-3035. doi: 10.1016/S0140-6736(16) 31593-8.

2. Fleischmann-Struzek C, Goldfarb DM, Schlattmann P, Schlapbach LJ, Reinhart K, Kissoon N. The global burden of paediatric and neonatal sepsis: a systematic review. Lancet Respir Med 2018;6:223230. doi: 10.1016/S2213-2600(18)30063-8.

3. Wang H, Yue H, Sun B, Zhu X, Niu H, Qi T, et al. Birth population survey in Huai'an in 2015: perinatal-neonatal mortality and preterm birth rate in emerging regions in China. J Matern Fetal Neonatal Med 2020;33:838-846. doi: 10.1080/14767058.2018.1506439.

4. He C, Chu Y, Perin J, Dai L, Li X, Miao L, et al. National and subnational all-cause and cause-specific child mortality in China, 1996-2015: a systematic analysis with implications for the sustainable development goals. Lancet Global Health 2017;5:e186-e197. doi: 10.1016/S2214-109X(16)30334-5.

5. Shane AL, Sànchez PJ, Stoll BJ. Neonatal sepsis. Lancet 2017;390:1770-1780. doi: 10.1016/S0140-6736(17)31002-4.

6. Goldenberg RL, Hauth JC, Andrews WW. Intrauterine infection and preterm delivery. N Engl J Med 2000;342:1500-1507. doi: 10.1016/ S0140-6736(17)31002-4.

7. Giannoni E, Agyeman PKA, Stocker M, Posfay-Barbe KM, Heininger $\mathrm{U}$, Spycher BD, et al. Neonatal sepsis of early onset, and hospitalacquired and community-acquired late onset: a prospective population-based cohort study. J Pediatr 2018;201:106-114. doi: 10.1016/j. jpeds.2018.05.048.

8. Saha S, Schrag SJ, Arifeen SE, Mullany LC, Shahidul Islam M, Shang $\mathrm{N}$, et al. Causes and incidence of community-acquired serious infections among young children in south Asia (ANISA): an observational cohort study. Lancet 2018;392:145-159. doi: 10.1016/j.jpeds.2018.05.048.

9. Schrag SJ, Farley MM, Petit S, Reingold A, Weston EJ, Pondo T, et al. Epidemiology of invasive early-onset neonatal sepsis, 2005 to 2014. Pediatrics 2016;138:e20162013. doi: 10;1542/peds2016-2013.

10. Stoll BJ, Hansen N, Fanaroff AA, Wright LL, Carlo WA, Ehrenkranz RA, et al. Changes in pathogens causing early-onset sepsis in verylow-birth-weight infants. N Engl J Med 2002;347:240-247. doi: 10.1007/s10096-014-2232-6.

11. Stoll BJ, Hansen NI, Sánchez PJ, Faix RG, Poindexter BB, Van Meurs $\mathrm{KP}$, et al. Early onset neonatal sepsis: the burden of Group B Streptococcal and E. coli disease continues. Pediatrics 2011;127:817826. doi: 10.1542/peds.2010-2217.

12. Heath PT, Balfour G, Weisner AM, Efstratiou A, Lamagni TL, Tighe $\mathrm{H}$, et al. Group B streptococcal disease in UK and Irish infants younger than 90 days. Lancet 2004;363:292-294. doi: 10.1016/ S0140-6736(03)15389-5.

13. Vergnano S, Menson E, Kennea N, Embleton N, Russell AB, Watts T, et al. Neonatal infections in England: the NeonIN surveillance network. Arch Dis Child Fetal Neonatal Ed 2011;96:F9-F14. doi: 10.1136/adc.2009.178798.

14. Dagnew AF, Cunnington MC, Dube Q, Edwards MS, French N, Heyderman RS, et al. Variation in reported neonatal group B streptococcal disease incidence in developing countries. Clin Infect Dis 2012;55:91-102. doi: 10.1093/cid/cis395.

15. Tiskumara R, Fakharee SH, Liu CQ, Nuntnarumit P, Lui KM, Hammoud M, et al. Neonatal infections in Asia. Arch Dis Child Fetal Neonatal Ed 2009;94:F144-F148. doi: 10.1136/adc.2008. 139865.

16. Al-Taiar A, Hammoud MS, Cuiqing L, Lee JK, Lui KM, Nakwan N, et al. Neonatal infections in China, Malaysia, Hong Kong and Thailand. Arch Dis Child Fetal Neonatal Ed 2013;98:F249-F255. doi: 10.1136/archdischild-2012-301767.

17. Jiang S, Hong L, Gai J, Shi J, Yang Y, Lee SK, et al. Early-onset sepsis among preterm neonates in China, 2015 to 2018. Pediatr Infect Dis J 2019;38:1236-1241. doi: 10.1097/INF.0000000000002492.

18. Prevention of group B Streptococcal early-onset disease in newborns: ACOG committee opinion, number 797. Obstet Gynecol 2020;135: e51-e72. doi: 10.1097/AOG.0000000000003669.

19. Bekker V, Bijlsma MW, van de Beek D, Kuijpers TW, van der Ende A. Incidence of invasive group B streptococcal disease and pathogen genotype distribution in newborn babies in the Netherlands over 25 years: a nationwide surveillance study. Lancet Infect Dis 2014;14:1083-1089. doi: 10.1016/S1473-3099(14)70919-3.

20. O'Sullivan CP, Lamagni T, Patel D, Efstratiou A, Cunney R, Meehan M, et al. Group B Streptococcal disease in UK and Irish infants younger than 90 days, 2014-15: a prospective surveillance study. Lancet Infect Dis 2019;19:83-90. doi: 10.1016/S1473-3099(18) 30555-3.

21. Kao Y, Tsai M-H, Lai M-Y, Chu S-M, Huang H-R, Chiang M-C, et al. Emerging serotype III sequence type 17 group B streptococcus invasive infection in infants: the clinical characteristics and impacts on outcomes. BMC Infect Dis 2019;19:538. doi: 10.1186/s12879019-4177-y.

22. Heyderman RS, Madhi SA, French N, Cutlard C, Ngwira B, Kayambo D, et al. Group B streptococcus vaccination in pregnant women with or without HIV in Africa: a non-randomised phase 2, open-label, multicentre trial. Lancet Infect Dis 2016;16:546-555. doi: 10.1016/S1473-3099(15)00484-3.

23. Huang J, Lin XZ, Zhu Y, Chen C. Epidemiology of Group B streptococcal infection in pregnant women and diseased infants in China. Pediatr Neonatol 2019;60:487-495. doi: 10.1016/j.pedneo.2019.07.001.

24. Ji W, Liu H, Madhi SA, Cunnington M, Zhang Z, Dangor Z, et al. Clinical and molecular epidemiology of invasive Group B Streptococcus disease among infants. China Emerg Infect Dis 2019;25:2021-2030. doi: 10.3201/eid2511.181647.

25. Han X, Du H, Cao Y, Zhang Y, Zhang J, Zhang L, et al. Association of histological and clinical chorioamnionitis with perinatal and neonatal outcome. J Matern Fetal Neonatal Med 2019;1-9. doi: 10.1080/14767058.2019.1618824.

26. Berardi A, Rossi C, Creti R, China M, Gherardi G, Venturelli C, et al. Group B streptococcal colonization in 160 mother-baby pairs: a prospective cohort study. J Pediatr 2013;163:1099-1104. doi: 10.1016/j.jpeds.2013.05.064. 
27. Dong Y, Glaser K, Speer CP. Late-onset sepsis caused by Gramnegative bacteria in very low birth weight infants: a systematic review. Expert Rev Anti Infect Ther 2019;17:177-188. doi: 10.1080/ 14787210.2019 .1568871$.

28. Okike IO, Johnson AP, Henderson KL, Blackburn RM, MullerPebody B, Ladhani SN, et al. Incidence, aetiology, and outcome of bacterial meningitis in infants aged $<90$ days in the UK and Republic of Ireland: prospective, enhanced, national population-based surveillance. Clin Infect Dis 2014;59:e150-e157. doi: 10.1093/cid/ciu514.

29. Gaschignard J, Levy C, Romain O, Cohen R, Bingen E, Aujard Y, et al. Neonatal bacterial meningitis: 444 cases in 7 years. Pediatr Infect Dis J 2011;30:212-217. doi: 10.1097/inf.0b013e3181fab1e7.

30. Basmaci R, Bonacorsi S, Bidet P, Biran V, Aujard Y, Bingen E, et al. Escherichia coli meningitis features in 325 children from 2001 to 2013 in France. Clin Infect Dis 2015;61:779-786. doi: 10.1093/cid/ civ367.

31. Folgori L, Tersigni C, Hsia Y, Kortsalioudaki C, Heath P, Sharland $\mathrm{M}$, et al. The relationship between Gram-negative colonization and bloodstream infections in neonates: a systematic review and metaanalysis. Clin Microbiol Infect 2018;24:251-257. doi: 10.1016/j. cmi.2017.08.008.

32. Thaver D, Zaidi AKM. Burden of neonatal infections in developing countries: a review of evidence from community-based studies. Pediatr Infect Dis J 2009;28 (Suppl 1):S3-S9. doi: 10.1097/ INF.0b013e3181958755.

33. Deen J, von Seidlein L, Andersen F, Elle N, White NJ, Lubell Y. Community-acquired bacterial bloodstream infections in developing countries in South and Southeast Asia: a systematic review. Lancet Infect Dis 2012;12:480-487. doi: 10.1016/S1473-3099(12)70028-2.

34. Huynh BT, Kermorvan-Duchemin E, Herindrainy P, Padget M, Rakotoarimanana FMJ, Feno $\mathrm{H}$, et al. Bacterial infections in neonates, Madagascar. Emerging Infect Dis 2018;24:710-717. doi: 10.3201/eid2404.161977.

35. Chessyre E, Goff Z, Bowen A, Carapetis J. The prevention, diagnosis and management of central venous line infections in children. J Infect 2015;71:S59-S75. doi: 10.1016/j.jinf.2015.04.029.

36. Kiroshita D, Hada S, Fujita R, Matsunaga N, Sakaki H, Ohki Y. Maximal sterile barrier precautions independently contribute to decreased central line-associated bloodstream infection in very low birth weight infants: a prospective multicenter observational study. Am J Infect Control 2019;47:1365-1369. doi: 10.1016/j.ajic.2019. 05.006.

37. Li JY, Chen SQ, Yan YY, Hu YY, Wei J, Wu QP, et al. Identification and antimicrobial resistance of pathogens in neonatal septicemia in China: a meta-analysis. Int J Infect Dis 2018;71:89-93. doi: 10.1016/ j.ijid.2018.04.794.

38. Lu Q, Zhou M, Tu Y, Yao Y, Yu J, Cheng S. Pathogen and antimicrobial resistance profiles of culture-proven neonatal sepsis in Southwest China. J Paediatr Child Health 2016;52:939-943. doi: 10.1111/jpc.13278.

39. Jiang Y, Kuang L, Wang H, Li L, Zhou W, Li M. The clinical characteristics of neonatal sepsis infection in Southwest China. Intern Med 2016;55:597-603. doi: 10.2169/internalmedicine.55.3930.

40. Li X, Ding X, Shi P, Zhu Y, Huang Y, Li Q, et al. Clinical features and antimicrobial susceptibility profiles of culture-proven neonatal sepsis in a tertiary children's hospital, 2013 to 2017. Medicine (Baltimore) 2019;98:e14686. doi: 10.1097/MD.0000000000014686.

41. Lin HJ, Du LZ, Ma XL, Shi LP, Pan JH, Tong XM, et al. Mortality and morbidity of extremely low birth weight infants in the mainland of China: a multi-center study. Chin Med J 2015;128:2743-2750. doi: 10.4103/0366-6999.167312.

42. Dong Y, Speer CP. Late-onset neonatal sepsis: recent developments. Arch Dis Child Fetal Neonatal Ed 2015;100:F257-F263. doi: 10.1136/archdischild-2014-306213.

43. Cruz AT, Freedman SB, Kulik DM, Okada PJ, Fleming AH, Mistry $\mathrm{RD}$, et al. Herpes simplex virus infection in infants undergoing meningitis evaluation. Pediatrics 2018;141:e20171688. doi: 10.1542/peds.2017-1688.

44. Lafolie J, Labbé A, L'Honneur AS, Madhi F, Pereira B, Decobert M, et al. Assessment of blood enterovirus testing in pediatric populations with fever without source, sepsis-like disease, or suspected meningitis: a prospective, multicentre, observational cohort study. Lancet Infect Dis 2018;18:1385-1396. doi: 10.1016/S1473-3099(18)30479-1.

45. Lv XQ, Qian LH, Wu T, Yuan TM. Enterovirus infection in febrile neonates: a hospital-based prospective cohort study. J Paediatr Child Health 2016;52:837-841. doi: 10.1111/jpc.13193.
46. Wu T, Fan XP, Wang WY, Yuan TM. Enterovirus infections are associated with white matter damage in neonates. J Paediatr Child Health 2014;50:817-822. doi: 10.1111/jpc.12656.

47. Yaacobi N, Bar-Meir M, Shchors I, Bromiker R. A prospective controlled trial of the optimal volume for neonatal blood cultures. Pediatr Infect Dis J 2015;34:351-354. doi: 10.1097/ INF.0000000000000594.

48. Lacroix LE, Vunda A, Bajwa NM, Galetto-Lacour A, Gervaix A. Catheterization of the urethra in male children. N Engl J Med 2010;363:e19. doi: 10.1056/NEJMvcm0808873.

49. Manzano S, Vunda A, Schneider F, Vandertuin L, Lacroix LE. Catheterization of the urethra in girls. N Engl J Med 2014;371:e2. doi: 10.1056/NEJMvcm1105612.

50. Ellemby MS, Tegmeyer K, Lai S, Braner DAV. Lumbar puncture. N Engl J Med 2006;355:e12. doi: 10.1056/NEJMvcm054952.

51. Galetto-Lacour A, Zamora SA, Andreola B, Bressan S, Lacroix L, Da Dalt L, et al. Validation of a laboratory risk index score for the identification of severe bacterial infection in children with fever without source. Arch Dis Child 2010;95:968-973. doi: 10.1136/ adc.2009.176800.

52. Coulthard MG, Kalra M, Lambert HJ, Nelson A, Smith T, Perry JD. Redefining urinary tract infections by bacterial colony counts. Pediatrics 2010;125:335-341. doi: 10.1542/peds.2008-1455.

53. Gomez B, Mintegui S, Bressan S, Da Dalt L, Gervaix A, Lacroix L, et al. Validation of the "Step-by-Step" approach in the management of young febrile infants. Pediatrics 2016;138:e20154381. doi: 10.1542/peds.2015-4381.

54. Kuppermann N, Dayan PS, Levine DA, Vitale M, Tzimenatos L, Tunik MG, et al. A clinical prediction rule to identify febrile infants 60 days and younger at low risk for serious bacterial infection. JAMA Pediatr 2019;173:342-351. doi: 10.1001/jamapediatrics.2018.5501.

55. Thomson J, Sucharew H, Cruz TA, Nigrovic LE, Freedman SB, Garro $\mathrm{AC}$, et al. Cerebrospinal fluid reference values for young infants undergoing lumbar puncture. Pediatrics 2018;141:e20173405. doi: 10.1542/peds.2017-3405.

56. Glimaker M, Sjölnin J, Akesson S, Naucler P. Lumbar puncture performed promptly or after neuroimaging in acute bacterial meningitis in adults: a prospective national cohort study evaluating different guidelines. Clin Infect Dis 2018;66:321-328. doi: 10.1093/ $\mathrm{cid} / \mathrm{cix} 806$.

57. Kim KS. Acute bacterial meningitis in infants and children. Lancet Infect Dis 2010;10:32-42. doi: 10.1016/S1473-3099(09) 70306-8.

58. Bailie HC, Arthurs OJ, Murray MJ, Kelsall AW. Weight-based determination of spinal canal depth for paediatric lumbar punctures. Arch Dis Child 2013;98:877-880. doi: 10.1136/archdischild-2013303793.

59. Collaborative Study Group for Neonatal Bacterial Meningitis. A multicenter epidemiological study of neonatal bacterial meningitis in parts of South China (in Chinese). Chin J Pediatr 2018;56:421-428. doi: 10.3760/cma.j.issn.0578-1310.2018.06.004.

60. Rao SC, Srinivasjois R, Moon K. One dose per day compared to multiple doses per day of gentamicin for treatment of suspected or proven neonatal sepsis. Cochrane Database Syst Rev 2016;12: CD005091. doi: 10.1002/14651858.CD005091.pub4.

61. McWilliam SJ, Antoine DJ, Smyth RL, Pirmohamed M. Aminoglycoside-induced nephrotoxicity in children. Pediatr Nephrol 2017;32:2015-2025. doi: 10.1007/s00467-016-3533-z.

62. Nguyen T, Jeyakumar A. Genetic susceptibility to aminoglycoside ototoxicity. Int J Pediatr Othorinolaryngol 2019;120:15-19. doi: 10.1016/j.ijporl.2019.02.002.

63. Janssen EJ, Välitalo PA, Allegaert K, de Cock RF, Simons SH, Sherwin CM, et al. Towards rational dosing algorithms for vancomycin in neonates and infants based on population pharmacokinetic modeling. Antimicrob Agents Chemother 2015;60:10131021. doi: 10.1128/AAC.01968-15.

64. Tauzin M, Cohen R, Durrmeyer X, Dassieu G, Barre J, Caeymaex L. Continuous-infusion vancomycin in neonates: assessment of dosing regimen and therapeutic proposal. Front Pediatr 2019;7:188. doi: 10.3389/fped.2019.00188.

65. Farzin A, Saha SK, Baqui AH, Choi Y, Ahmed NU, Simoes EAF, et al. Population-based incidence and etiology of community-acquired neonatal viral infections in Bangladesh. Pediatr Infect Dis J 2015;34:706-711. doi: 10.1097/INF.0000000000000726.

66. Puopolo KM, Benitz WE, Zaoutis TE. Committee on fetus and neonate, Committee on infectious diseases of the American Academy 
of Pediatrics. Management of neonates born at $\leq 34$ 6/7 weeks gestation with suspected or proven early-onset bacterial sepsis. Pediatrics 2018;142:e20182896. doi: 10.1542/peds.2018-2896.

67. Puopolo KM, Benitz WE, Zaoutis TE. Committee on fetus and neonate, Committee on infectious diseases of the American Academy of Pediatrics. Management of neonates born at 35 0/7 weeks' gestation with suspected or proven early-onset bacterial sepsis. Pediatrics 2018;142:e20182894. doi: 10.1542/peds.2018-2894.

68. Tunkel AR, Hartman BJ, Kaplan SL, Kaufman BA, Roos KL, Scheld WM, et al. Practice guidelines for the management of bacterial meningitis. Clin Infect Dis 2004;39:1267-1284. doi: 10.1086/ 425368.

69. Hanretty AM, Gallagher JC. Shortened courses of antibiotics for bacterial infections: a systematic review of randomized clinical trials. Pharmacotherapy 2018;38:674-687. doi: 10.1002/phar.2118.

70. Stocker M, van Herk W, el Helou S, Dutta S, Fontana MS, Shuerman FABA, et al. Procalcitonin-guided decision making for duration of antibiotic therapy in neonates with suspected early-onset sepsis: a multicentre, randomised controlled trial (NeoPIns). Lancet 2017;390:871-881. doi: 10.1016/S0140-6736(17)31444-7.

71. Zhang J, Folgori L, Hsia Y, Sharland M, Yang Y. Pattern of antibiotic resistance in bloodstream isolates from Chinese neonates. Pediatr Infect Dis J 2019;38:600-604. doi: 10.1097/INF.00000000000 02246.

72. Ding Y, Wang Y, Hsia Y, Sharland M, Heath PT. Systematic review of carbapenem-resistant Enterobacteriaceae causing neonatal sepsis in China. Ann Clin Microbiol Antimicrob 2019;18:36. doi: 10.1186/ s12941-019-0334-9.

73. Li G, Bielicki JA, Ahmed ASMNU, Islam MS, Berezin EN, Gallacci $\mathrm{CB}$, et al. Towards understanding global patterns of antimicrobial use and resistance in neonatal sepsis: insights from the NeoAMR network. Arch Dis Child 2020;105:26-31. doi: 10.1136/archdischild-2019-316816.

74. Investigators of the Delhi Neonatal Infection Study (DeNIS) Collaboration. Characterisation and microbial resistance of sepsis pathogens in neonates born in tertiary care centres in Delhi, India: a cohort study. Lancet Global Health 2016;4:e752-e760. doi: 10.1016/S2214-109X(16)30148-6.

75. Nour I, Eldegla HE, Nasef N, Shouman B, Abdel-Hady H, Shabaan AE. Risk factors and clinical outcomes for carbapenem-resistant
Gram-negative late-onset sepsis in a neonatal intensive care unit. J Hosp Infect 2017;97:52-58. doi: 10.1016/j.jhin.2017.05.025.

76. Donà D, Sharland M, Heath PT, Folgori L. Strategic trials to define the best available treatment for neonatal and pediatric sepsis caused by carbapenem-resistant organisms. Pediatr Infect Dis J 2019;38:825-827. doi: 10.1097/INF.0000000000002381.

77. Cantey JB, Wozniak PS, Pruszynski JE, Sánchez PJ. Reducing unnecessary antibiotic use in the neonatal intensive care unit (SCOUT): a prospective interrupted time-series study. Lancet Infect Dis 2016;16:1178-1184. doi: 10.1016/S1473-3099(16)30205-5.

78. Seidel J, Haller S, Eckmanns T, Harder T. Routine screening for colonization by GNB in neonates at intensive care units for the prediction of sepsis: systematic review and meta-analysis. J Hosp Infect 2018;99:367-380. doi: 10.1016/j.jhin.2018.03.017.

79. Tacconelli E, Cataldo MA, Dancer SJ, De Angelis G, Falcone M, Frank U, et al. ESCMID guidelines for the management of the infection control measures to reduce transmission of multidrugresistant Gram-negative bacteria in hospitalized patients. Clin Microbiol Infect 2014;20 Suppl 1:1-55. doi: 10.1111/14690691.12427.

80. Maitland K, Kiguli S, Opoka RO, Engoru C, Olupot-Olupot P, Akech $\mathrm{SO}$, et al. Mortality after fluid bolus in African children with severe infection. N Engl J Med 2011;364:2483-2495. doi: 10.1056/ NEJMoa1101549.

81. Levin M, Cunnington AJ, Wilson C, Nadel S, Lang HJ, Ninis N, et al. Effects of saline or albumin bolus in resuscitation: evidence from reanalysis of the FEAST trial. Lancet Respir Med 2019;7:581-593. doi: 10.1016/S2213-2600(19)30114-6.

82. The INIS Collaborative Group. Treatment of neonatal sepsis with intravenous immune globulin. N Engl J Med 2011;365:1201-1211. doi: 10.1056/NEJMoa1100441.

83. Chatterjee A, Modarai M, Naylor NR, Boyd SE, Atun R, Barlow J, et al. Quantifying drivers of antibiotic resistance in humans: a systematic review. Lancet Infect Dis 2018;18:e368-e378. doi: 10.1016/S1473-3099(18)30296-2.

How to cite this article: Dong Y, Basmaci R, Titomanlio L, Sun B, Mercier JC. Neonatal sepsis: within and beyond China. Chin Med J 2020;00:0000. doi: 10.1097/CM9.0000000000000935 